\title{
Article \\ Academ Virus, a Novel Hantavirus in the Siberian Mole (Talpa altaica) from Russia
}

\author{
Liudmila N. Yashina ${ }^{1, *}$, Victor V. Panov ${ }^{2}$, Sergey A. Abramov ${ }^{2} \mathbb{}$, Natalia A. Smetannikova ${ }^{1}$, \\ Ekaterina M. Luchnikova ${ }^{3}$, Tamara A. Dupal ${ }^{2}$, Anton V. Krivopalov ${ }^{2}$, Satoru Arai ${ }^{4} \mathbb{C}$ \\ and Richard Yanagihara ${ }^{5, *(1)}$
}

1 State Research Center of Virology and Biotechnology VECTOR, 630559 Koltsovo, Russia; smetannikova@vector.nsc.ru

2 Institute of Systematics and Ecology of Animals, 630091 Novosibirsk, Russia; panovv53@mail.ru (V.V.P.); terio@eco.nsc.ru (S.A.A.); dupalgf54@gmail.com (T.A.D.); krivopalov@gmail.com (A.V.K.)

3 Department of Ecology and Environmental Management, Institute of Biology, Ecology and Natural Resources, Kemerovo State University, 650099 Kemerovo, Russia; lut@yandex.ru

4 Center for Surveillance, Immunization, and Epidemiologic Research, National Institute of Infectious Diseases, Tokyo 162-8640, Japan; arais@nih.go.jp

5 John A. Burns School of Medicine, University of Hawaii at Manoa, Honolulu, HI 96813, USA

* Correspondence: yashina@vector.nsc.ru (L.N.Y.); ryanagih@hawaii.edu (R.Y.)

Citation: Yashina, L.N.; Panov, V.V.; Abramov, S.A.; Smetannikova, N.A.; Luchnikova, E.M.; Dupal, T.A.; Krivopalov, A.V.; Arai, S.; Yanagihara, R. Academ Virus, a Novel Hantavirus in the Siberian Mole (Talpa altaica) from Russia. Viruses 2022, 14, 309. https: / / doi.org/10.3390/v14020309

Academic Editors: Kumiko Yoshimatsu and Hiroaki Kariwa

Received: 31 December 2021

Accepted: 31 January 2022

Published: 2 February 2022

Publisher's Note: MDPI stays neutral with regard to jurisdictional claims in published maps and institutional affiliations.

Copyright: (C) 2022 by the authors. Licensee MDPI, Basel, Switzerland. This article is an open access article distributed under the terms and conditions of the Creative Commons Attribution (CC BY) license (https:// creativecommons.org/licenses/by/ $4.0 /)$.

\begin{abstract}
To date, six hantavirus species have been detected in moles (family Talpidae). In this report, we describe Academ virus (ACDV), a novel hantavirus harbored by the Siberian mole (Talpa altaica) in Western Siberia. Genetic analysis of the complete S-, M-, and partial L-genomic segments showed that ACDV shared a common evolutionary origin with Bruges virus, previously identified in the European mole (Talpa europaea), and is distantly related to other mole-borne hantaviruses. Co-evolution and local adaptation of genetic variants of hantaviruses and their hosts, with possible reassortment events, might have shaped the evolutionary history of ACDV.
\end{abstract}

Keywords: Hantaviridae; hantavirus; mole; evolution; Russia

\section{Introduction}

Recently, the host range of hantaviruses (family Hantaviridae) has been expanded with the discovery of genetically distinct hantaviruses in multiple species of shrews, moles, and bats [1,2]. Although several rodent-borne hantaviruses are known to cause hemorrhagic fever with renal syndrome or hantavirus cardiopulmonary syndrome [3,4], the pathogenicity of non-rodent-associated hantaviruses remains unclear, despite the infrequent detection of antibodies against certain shrew-borne hantaviruses in humans $[5,6]$. The genome of hantaviruses comprises three negative-polarity RNA segments: small (S), medium (M), and large (L), encoding a nucleocapsid (N) and occasionally nonstructural (NSs) protein, envelope glycoproteins (Gn and Gc), and an RNA-dependent RNA polymerase (RdRP), respectively. Currently, mammalian-associated hantaviruses are classified into four genera: Orthohantavirus, Loanvirus, Mobatvirus, and Thottimvirus [7].

With the discovery of highly divergent hantaviruses in shrews, moles, and bats [1,2], long-held hypotheses of the co-evolution of rodent-borne hantaviruses and their hosts have changed to concepts of a far more complex evolutionary history, with cross-species transmission and host switching [8-13] and reassortment events [14-18]. Genetically distinct hantaviruses have been identified in five species of moles (family Talpidae) from Eurasia and North America and mole-borne hantaviruses demonstrate distinct evolutionary histories [9,17,19-22]. The first mole-borne hantavirus, Nova virus (NVAV) [21], is widespread across the geographic distribution of its host, the European mole (Talpa europaea) [23]. Phylogenetic analysis of the full-length segments showed that NVAV was most closely related to hantaviruses harbored by bats and classified in the Mobatvirus genus. 
Recently, NVAV and Bruges virus (BRGV) were found co-circulating among European moles in Belgium, Germany, and the United Kingdom [17]. Phylogenetic placement of one of these viruses (BRGV, member of Orthohantavirus genus) corresponded to the co-evolution hypothesis, while the position of the second hantavirus (NVAV, member of Mobatvirus genus) suggested cross-species transmission and an ancient reassortment event. Parallel evolution associated with cross-species transmission had been shown for other orthohantaviruses harbored by shrew moles. Phylogenetic analysis and hostparasite evolutionary comparisons showed that Asama virus (ASAV) from the Japanese shrew mole (Urotrichus talpoides) and Oxbow virus (OXBV) from the American shrew mole (Neurotrichus gibbsii) were related to soricine shrew-borne hantaviruses from Eurasia and North America, respectively $[9,20]$.

Host-switching events have been suggested between mole-borne and rodent-borne hantaviruses. Rockport virus (RKPV) identified in the eastern mole (Scalopus aquaticus) shared a more recent common ancestor with cricetid-rodent-borne hantaviruses, which are sympatric across the eastern United States [22]. Dahonggou Creek virus (DHCV), harbored by the long-tailed mole (Scaptonyx fusicaudus), is a member of the Thottimvirus genus, joining crocidurine and myosoricine shrew-borne hantaviruses [19]. Further investigation of hantavirus-reservoir relationships among moles is important for understanding hantavirus evolution. Here, we report the detection, genomic characterization, and geographic distribution of a new hantavirus, named Academ virus (ACDV), in the Siberian mole (Talpa altaica).

\section{Materials and Methods}

\subsection{Trapping and Sample Collection}

During June to August 2017-2021, Siberian moles were trapped in Western Siberia, Russia. All wildlife field operations, including the responsible treatment of animals, met the guideline requirements of the order of the Russian High and Middle Education Ministry (No. 742 issued on 13 November 1984) and by the Federal Law of the Russian Federation (No. 498-FZ issued on 19 December 2018). Collection sites in the Novosibirsk Oblast were located near Academgorodok town, separate district of Novosibirsk City $\left(54.82484^{\circ} \mathrm{N} / 83.09392^{\circ} \mathrm{E}\right)$, Teletskoye Lake $\left(51.79424^{\circ} \mathrm{N} / 87.30447^{\circ} \mathrm{E}\right)$ in the Altai Republic, and around the settlement Azhendarovo (54.76237 ${ }^{\circ} \mathrm{N} / 87.03094^{\circ} \mathrm{E}$ and $54.74537^{\circ} \mathrm{N} / 87.02093^{\circ} \mathrm{E}$ ) in the Kemerovo Oblast. Permanent pitfall traps were used to capture moles near Academgorodok and around Azhendarovo. Lethal spring-loaded scissor traps, placed in burrows, were used at Teletskoye Lake. Lung samples were collected aseptically and stored in RNAlater ${ }^{\mathrm{TM}}$ (Qiagen, Hilden, Germany) before analysis.

\subsection{RNA Extraction and RT-PCR Analysis}

Total RNA was extracted from lung tissues, using the RNeasy MiniKit (Qiagen, Hilden, Germany), then reverse transcribed, using the Expand reverse transcriptase (Roche, Basel, Switzerland) with universal oligonucleotide primer (OSM55, 5'-TAGTAGTAGACTCC-3'), designed from the conserved $3^{\prime}$ end of the S-, $\mathrm{M}-$, and L-segments of hantaviruses. For initial screening by nested RT-PCR, previously described genus-specific oligonucleotide primers targeting the partial L-segment sequence were used [24]. Oligonucleotide primers specific for ACDV S and M-segments (Supplementary Table S1) were designed from consensus regions of other hantaviruses. Amplicons were separated by electrophoresis on $1.2 \%$ agarose gels and purified using the QIAQuick Gel Extraction Kit (Qiagen, Hilden, Germany). DNA was sequenced directly using an ABI Prism 310 Genetic Analyzer (Applied Biosystems, Foster City, CA, USA).

\subsection{Genetic and Phylogenetic Analysis}

Pairwise alignment and comparison of full-length coding regions of the S-, M-, and partial L-segment nucleotide and amino acid sequences of hantaviruses from T. altaica, captured in Russia, with representative rodent-, shrew-, mole-, and bat-borne hantaviruses 
were performed, using the ClustalW in BioEdit [25-27]. Phylogenetic trees were generated using the Markov chain Monte Carlo (MCMC) methods MrBayes 3.1.2 [28], under the best-fit general time-reversible model of nucleotide evolution with gamma-distributed rate heterogeneity and invariable sites $(\mathrm{GTR}+\mathrm{I}+\Gamma)$ [29]. The best-fit model was selected with jModelTest version 2.1.9 [30] for phylogenetic trees. Two replicate Bayesian MetropolisHastings MCMC runs, each consisting of six chains of 10 million generations sampled every 100 generations with a burn-in of 25,000 (25\%), resulted in 150,000 trees overall.

\section{Results}

\subsection{Genetic Analysis}

During 2017-2021, 18 Siberian moles were captured at three localities of Novosibirsk, Kemerovo Oblast, and Altai Republic, in Western Siberia (Table 1 and Figure 1). RNAlater ${ }^{\mathrm{TM}_{-}}$ preserved lung specimens were analyzed for hantavirus RNA by nested RT-PCR using oligonucleotide primers directed at the RdRP gene. Hantaviral RNA was detected in 14 of 18 Siberian moles $(77.8 \%)$. The geographic distribution of positive samples included all three sampling sites. A new hantavirus was detected in one of two Siberian moles, captured in 2017 in the forest surrounding Academgorodok, a separate district of Novosibirsk City. The 346-nucleotide fragment of the L-segment displayed relatively low sequence similarity to other hantaviruses and was most closely related to BRGV. This new hantavirus was designated ACDV strain Academ-Ta450/Russia/2017 according to the capture site. Further analysis of five hantavirus-positive samples collected in 2019 and 2021 (Table 1) in the same site demonstrated close identity of partial L-segment sequences (98.0-99.7\% nucleotide and $100 \%$ amino acid identity). By contrast, ACDV sequences recovered from six of seven Siberian moles captured in 2018 and 2020 near Teletskoye Lake, Altai Republic, demonstrated a higher level of sequence divergence between each other (0.3-11.8\% nucleotide, $0-1.7 \%$ amino acid). Moreover, relatively diverse ACDV sequences were detected between two of four Siberian moles captured at the third locality, Azhendarovo in Kemerovo Oblast (14.9\% nucleotide, 1.7\% amino acid). Although ACDV strains from the three sites had nucleotide identities ranging from 80.7 to $84.2 \%$, the corresponding amino acid sequences were highly conserved (96.5-99.1\%).

Table 1. Prevalence of hantavirus RNA and hantavirus sequences in Talpa altaica from Siberia, Russia.

\begin{tabular}{|c|c|c|c|c|c|c|}
\hline Capture Site & \multicolumn{3}{|c|}{$\begin{array}{l}\text { Number Hantavirus } \\
\text { Positive/Tested }\end{array}$} & \multicolumn{3}{|c|}{ GenBank No. } \\
\hline \multirow{6}{*}{$\begin{array}{l}\text { Novosibirsk Oblast, } \\
\text { Academgorodok }\end{array}$} & \multirow[t]{2}{*}{2017} & \multirow[t]{2}{*}{$1 / 2$} & Academ-Ta450 & MK340905 & OL871119 & MH784614 \\
\hline & & & Academ-Ta348 & - & - & MZ062416 \\
\hline & \multirow[t]{2}{*}{2019} & \multirow[t]{2}{*}{$3 / 3$} & Academ-Ta400 & - & - & MZ062417 \\
\hline & & & Academ-Ta589 & - & - & MZ062418 \\
\hline & \multirow{2}{*}{2021} & \multirow{2}{*}{$2 / 2$} & Academ-Ta68 & - & - & OL871122 \\
\hline & & & Academ-Ta101 & - & - & OL871123 \\
\hline \multirow{6}{*}{$\begin{array}{l}\text { Altai Republic, } \\
\text { Teletskoye }\end{array}$} & \multirow[t]{2}{*}{2018} & \multirow[t]{2}{*}{$1 / 1$} & Telet-Ta78 & & & MZ062419 \\
\hline & & & Telet-Ta601 & MZ062425 & - & MZ062420 \\
\hline & \multirow{4}{*}{2020} & \multirow{4}{*}{$5 / 6$} & Telet-Ta602 & - & - & MZ062421 \\
\hline & & & Telet-Ta603 & MZ062426 & - & MZ062422 \\
\hline & & & Telet-Ta604 & - & - & MZ062423 \\
\hline & & & Telet-Ta615 & MZ062427 & - & MZ062424 \\
\hline \multirow{2}{*}{$\begin{array}{l}\text { Kemerovo Oblast, } \\
\text { Azhendarovo }\end{array}$} & \multirow{2}{*}{2021} & \multirow{2}{*}{$2 / 4$} & Azhen-Ta261 & OL871120 & - & OL871124 \\
\hline & & & Azhen-Ta322 & OL871121 & - & OL871125 \\
\hline
\end{tabular}

\footnotetext{
"-" sequences unavailable.
} 


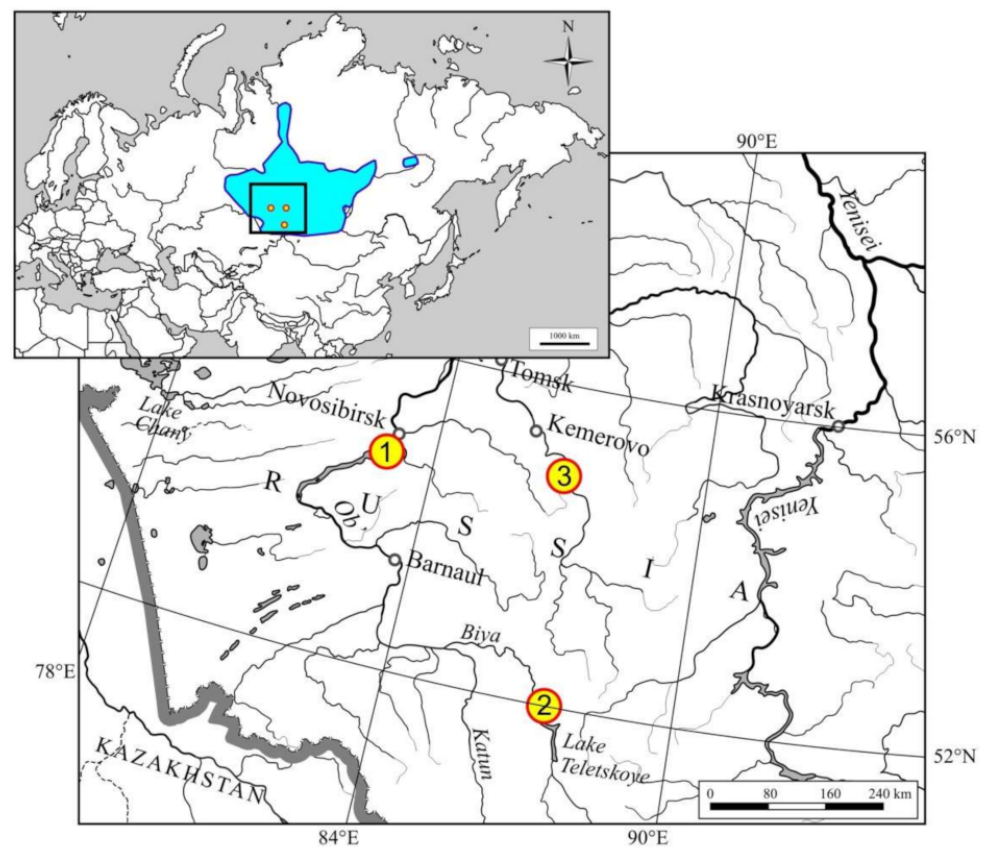

Figure 1. Map, showing the locations of the collection sites in West Siberia, Russia, where hantavirusinfected Siberian moles were captured. (1) Academgorodok, (2) Teletskoye, (3) Azhendarovo. The inset shows the geographic range of Talpa altaica (area colored in blue).

The 1791-nucleotide S-segment of ACDV (prototype strain Academ-Ta450/Russia/2017) encoded an $\mathrm{N}$ protein of 430 amino acids in length. An additional open reading frame on the nonstructural NSs protein was not present as in other mole-borne hantaviruses. The intraspecies variability of the new virus was estimated based on complete S-segment coding sequences that were recovered from six hantavirus RNA-positive samples. These new strains showed divergent L-segment sequences and were found in three geographically distant sites (strains Academ-Ta450, Telet-Ta601, Telet-Ta603, Telet-Ta615, Azhen-Ta261, Azhen-Ta322). The coding sequences of the new strains were of the same length, minor insertions/deletions were observed in the noncoding $3^{\prime}$ termini. Comparative analysis demonstrated relatively high genetic diversity between new strains, $3.6-16.3 \%$ at the nucleotide level, while the amino acid sequences were conserved (divergence was less than $1.4 \%)$. Pairwise alignment and comparison of the ACDV S-segment with representative hantaviruses belonging to the four genera of the Mammantavirinae subfamily (Figure 2) showed considerable divergence, ranging between $31-47 \%$ and $26-53 \%$ at the nucleotide and amino acid level, respectively.

The complete 3648-nucleotide M-segment of ACDV (prototype strain Academ-Ta450/ Russia /2017) contained a single ORF encoding the 1138-amino acid glycoprotein precursor (GP) of the Gn and Gc glycoproteins, separated by a WAVSA pentapeptide. The same motif was found in hantavirus ALTV (ALT302) and LENV (Khekhtsir-Sc67) from Sorex shrews in Russia and BRGV from the European mole (BE/Vieux-Genappe/TE/2013) in Belgium [17,31,32]. Analysis of the complete M-coding sequence revealed more than $29 \%$ nucleotide and amino acid sequence differences between ACDV and the most closely related BRGV virus (strains BE/Vieux-Genappe/TE/2013, DE/Wandlitz/TE/2013) and considerable divergence from other representative hantaviruses both at the nucleotide ( $>35 \%)$ and amino acid (>37\%) levels. The observed amino acid pairwise evolutionary distance (PED) values ranged between 0.3 and 1.0, thus exceeding current species demarcation criteria of a PED cut-off value of 0.1 [7], suggesting that ACDV represents a new hantavirus species. 


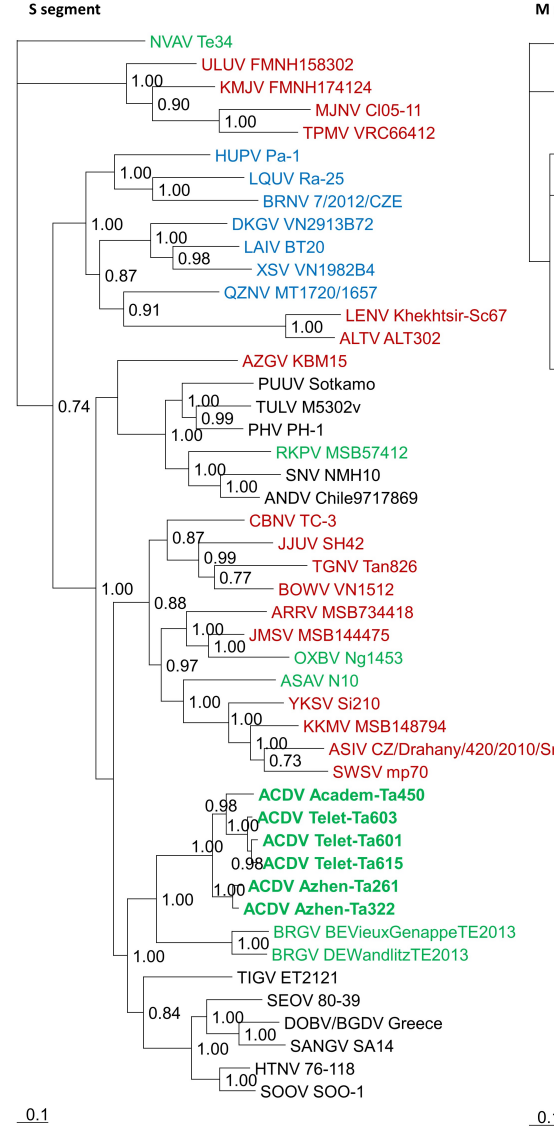

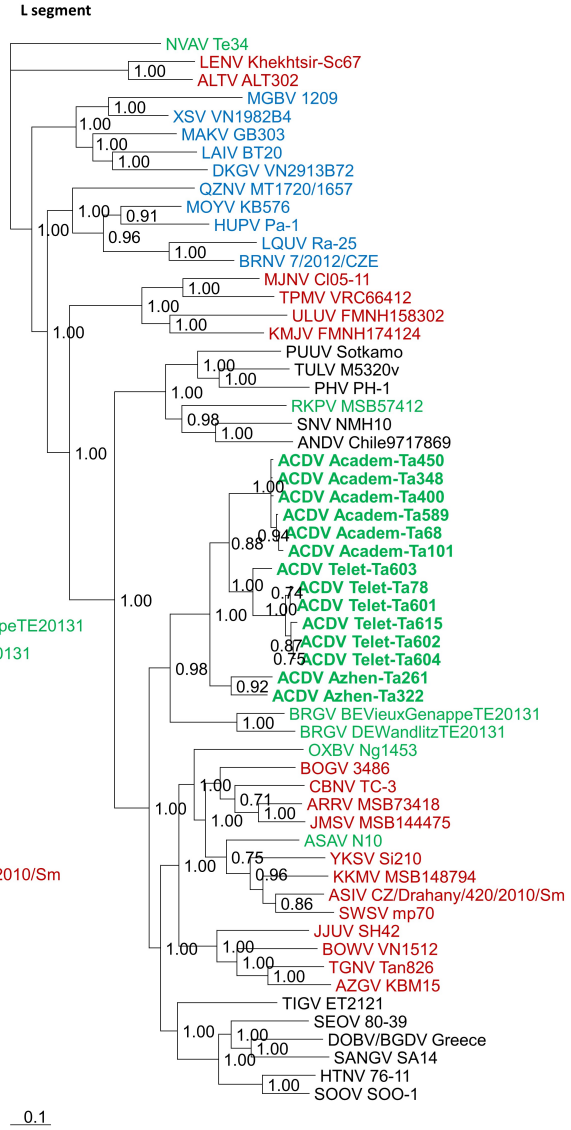

0.1

Figure 2. Phylogenetic trees generated by the Bayesian method, under the best-fit $\mathrm{GTR}+\mathrm{I}+\Gamma$ model of evolution, based on the S-, M-, and L-genomic segments of ACDV (green, bold lettering). The phylogenetic positions of ACDV strains in Russia are shown in relationship to mole-borne hantaviruses (green): Asama orthohantavirus (ASAV N10, S: EU929072; M: EU929075; L: EU929078) from Urotrichus talpoides, Nova mobatvirus (NVAV Te34, S: KR072621, M: KR072622, L: KR072623), and Bruges orthohantavirus (BRGV BE/VieuxGenappeTE2013, S: KR072621; M: KR072622; L: KR072623 and BRGV DEWandlitzTE2013, S: MF683844; M: MF683845; L: MF683846) from Talpa europaea, Rockport orthohantavirus (RKPV MSB57412, S: HM015223; M: HM015222; L: HM015221) from Scalopus aquaticus, and Oxbow orthohantavirus (OXBV Ng1453, S: FJ5339166; M: FJ539167; L: FJ593497) from Neurotrichus gibbsii. Shrew-borne hantaviruses (red lettering) include Thottapalayam thottimvirus (TPMV VRC66412, S: AY526097, M: EU001329, L: EU001330) from Suncus murinus, Imjin thottimvirus (MJNV C105-11, S: EF641804; M: EF641798; L: EF641806) from Crocidura lasiura, Uluguru thottimvirus (ULUV FMNH158302, S: JX193695; M: JX193696; L: JX193697) from Myosorex geata, Kilimanjaro thottimvirus (KMJV FMNH174124, S: JX193698; M: JX193699; L: JX193700) from Myosorex zinki, Jeju orthohantavirus (JJUV SH42, S: HQ663933; M: HQ663934; L: HQ663935) from Crocidura shantungensis, Cao Bằng orthohantavirus (CBNV TC-3, S: EF543524; M: EF543526; L: EF543525) from Anourosorex squamipes, Azagny orthohantavirus (AZGV KBM15, S: JF276226; M: JF276227; L: JF276228) from Crocidura obscurior, Bowé orthohantavirus (BOWV VN1512, S: KC631782; M: KC631783; L: KC631784) from Crocidura douceti, prototype Seewis orthohantavirus (SWSV mp70, S: EF636024; M: EF636025; L: EF636026), and Altai virus (ALTV ALT302, S: MK340902; M: MK340903; L: MT648514) from Sorex araneus, Lena virus (LENV Khekhtsir-Sc67, S: MH499470; M: MH499471; L: MH499472) from Sorex caecutiens, Asikkala virus (ASIV CZ/Drahany/420/2010/Sm, S: KC880342; M: KC880345; L: KC880348) from Sorex minutus, Jemez Springs orthohantavirus (JMSV MSB144475, S: FJ593499; M: FJ593500; L: FJ593501) from Sorex monticolus, Tanganya virus (TGNV Tan826, S: EF050455; L: EF050454) from Crocidura theresea, Ash River virus (ARRV MSB73418, S: EF650086; L: EF619961) from Sorex cinereus, Yakeshi virus (YKSV Si-210, S: JX465423; M: JX465403; L: JX465389) from Sorex isodon, Kenkeme virus (KKMV MSB148794, S: GQ306148; M: GQ306149; L: GQ306150 and KKMV Fuyuan 
Sr326, S: NC_034559; M: KJ857337; L: KJ857320) from Sorex roboratus, and Boginia virus (BOGV 3486, L: KM394262) from Neomys fodiens. Also shown are representative rodent-borne hantaviruses (black lettering), including Sin Nombre orthohantavirus (SNV NMH10, S: NC_005216; M: NC_005215; L: NC_005217), Andes orthohantavirus (ANDV Chile9717869, S: AF291702; M: AF291703; L: AF291704), Prospect Hill orthohantavirus (PHV PH-1, S: Z49098; M: X55129; L: EF646763), Tula orthohantavirus (TULV M5302v, S: NC_005227; M: NC_005228; L: NC_005226), Puumala orthohantavirus (PUUV Sotkamo, S: NC_005224; M: NC_005223; L: NC_005225), Sangassou orthohantavirus (SANGV SA14, S: JQ082300; M: JQ082301; L: JQ082302), Soochong orthohantavirus (SOOV SOO1, S: AY675349; M: AY675353; L: DQ056292), Dobrava/Belgrade orthohantavirus (DOBV/BGDV Greece, S: NC_005233; M: NC_005234; L: NC_005235), Hantaan orthohantavirus (HTNV 76-118, S: NC_005218; M: NC_005219; L: NC_005222), and Seoul orthohantavirus (SEOV 80-39, S: NC_005236; M: NC_005237; L: NC_005238), and Tigray virus (TIGV ET2121, S: KU934010; M: KU934009; L: KU934008) from Stenocephalemys albipes. Bat-borne hantaviruses (blue lettering) include Brno loanvirus (BRNV 7/2012/CZE, S: KX845678; M: KX845679; L: KX845680) from Nyctalus noctula, Láibīn mobatvirus (LAIV BT20, S: KM102247; M: KM102248; L: KM102249) from Taphozous melanopogon, Xuân Sơn mobatvirus (XSV VN1982B4, S: KC688335; L: JX912953) from Hipposideros pomona, Quezon mobatvirus (QZNV MT1720/1657, S: KU950713; M: KU950714; L: KU950715) from Rousettus amplexicaudatus, Mouyassué virus (MOYV KB576, L: JQ28771) from Neoromicia nanus, Makokou virus (MAKV GB303, L: KT316176) from Hipposideros ruber, Huángpí virus (HUPV Pa-1, S: JX473273, and L: JX465369) from Pipistrellus abramus, Lóngquán loanvirus (LQUV Ra-25, S: JX465415; M: JX465397; and L: JX465381) from Rhinolophus sinicus, Đakrông mobatvirus (DKGV VN2913B72, S: MG663536; M: MG663535; L: MG663534) from Aselliscus stoliczkanus, respectively. The numbers at each node are posterior node probabilities (>0.7), based on 150,000 trees: two replicate Markov Chain Monte Carlo runs consisting of six chains of 10 million generations each sampled every 100 generations with a burn-in of 25,000 $(25 \%)$. The scale bar indicates the nucleotide substitutions per site.

\subsection{Phylogenetic Analysis}

Phylogenetic trees, based on the coding regions of the full-length S-, M, and partial L-segments, were constructed by Bayesian methods. A phylogenetic tree of the S-segment demonstrated that ACDV from six Siberian moles had a common ancestry with BRGV from two European moles, segregated into separate clades with host species, and revealed the closest relationship to hantaviruses associated with hosts from the Muridae family (Figure 2). ACDV strains were divided into three sublineages with clear geographic clusters. Strains from Academgorodok were grouped into one sublineage, strains from Teletskoye formed a second sublineage, and strains from Azhendarovo were divided into another sublineage. A phylogenetic tree of the 14 partial L-segment sequences revealed similar topology. A phylogenetic tree of the complete coding sequence of the M-segment showed that ACDV and BRGV clustered closer to hantaviruses associated with hosts from the Soricidae family, suggesting possible reassortment events during the evolution of ACDV and BRGV.

Phylogenetic analysis of the cytochrome b (cyt B) gene from ACDV-positive moles confirmed the host identity as Talpa altaica (GenBank Accession Number OL977079-OL977088). Newly acquired host mtDNA sequences from Siberian moles segregated into distinct geographic-specific lineages (Figure 3). Sequences from Siberian moles, captured at Teletskoye and Azhendarovo, differentiated into three and two sublineages, respectively. Moles, captured at Academgorodok, had minimal cyt B sequence diversity and grouped into a single sublineage (Figure 3). 
Elephantulus rupestris, DQ901201 Elephantulus intufi, DQ901206

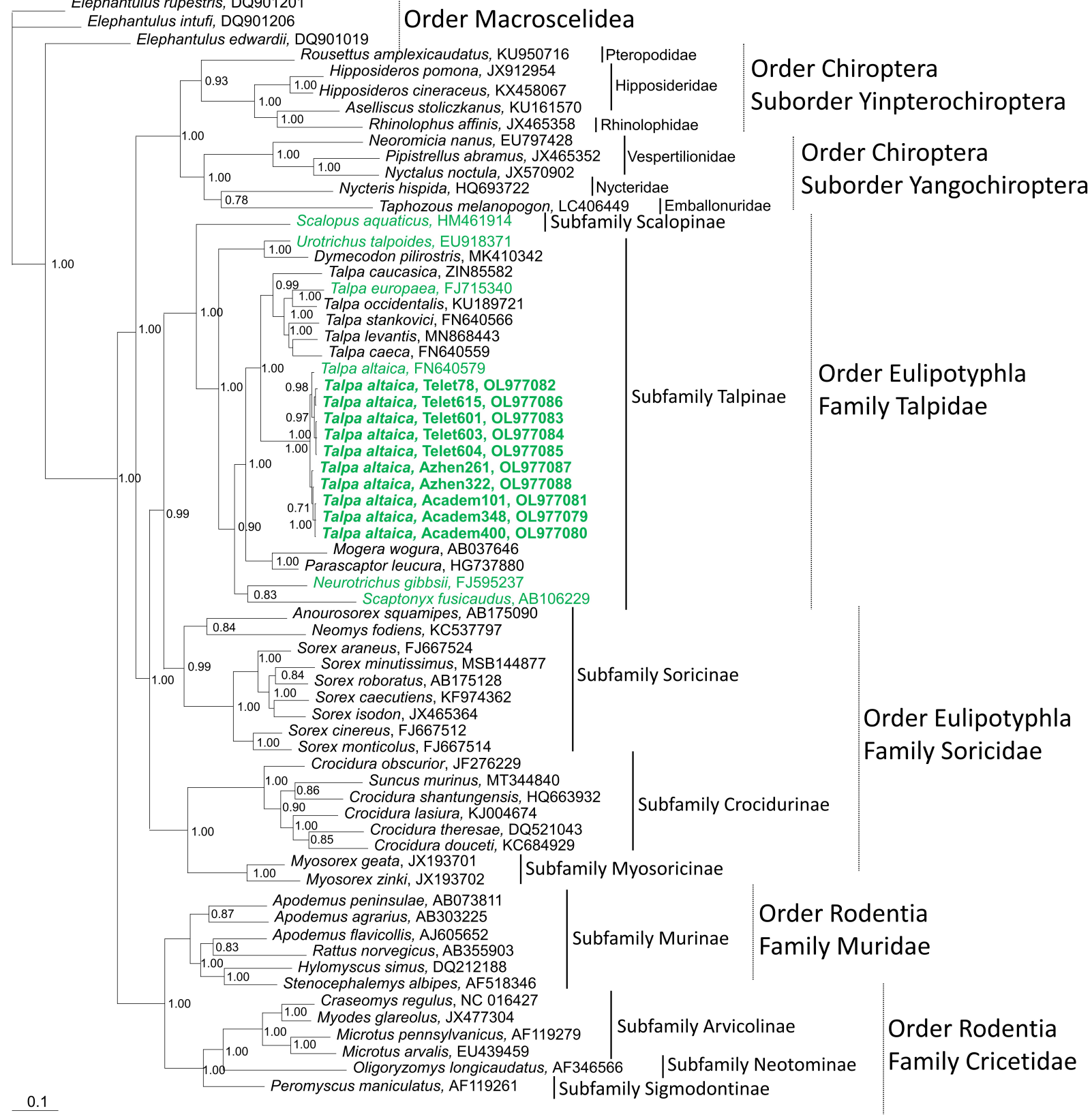

Figure 3. Bayesian phylogenetic tree based on 1140 nucleotides of the cytochrome b mtDNA of shrews and moles (order Eulipotyphla, families Talpidae and Soricidae), rodents (order Rodentia, families Muridae and Cricetidae), and bats (order Chiroptera, suborders Yinpterochiroptera and Yangochiroptera). The tree was rooted using Elephantulus (order Macroscelidea, GenBank Nos. DQ901019, DQ901206, and DQ901201) as the outgroup. FN640579 is from a Siberian mole captured in Teletskoye. Talpa altaica from this study are shown in bolded green lettering. Other mole species harboring hantaviruses are shown in unbolded green lettering. The number at each node indicates posterior probability values (>0.7), based on 15,000 trees: two replicate Markov chain Monte Carlo runs, consisting of six chains of one million generations each sampled every 100 generations with a burn-in of 2500 (25\%). The scale bar indicates the number of nucleotide substitutions per site. GenBank accession numbers are shown for taxa. 


\section{Discussion}

Here, we describe a new hantavirus, named ACDV, in the Siberian mole, captured in Western Siberia. ACDV from three geographically distant localities segregated along geographic-specific lineages. Phylogenetic analysis based on complete S- and M-segment sequences showed that the new hantavirus had a common evolutionary origin with BRGV, harbored by the phylogenetically related European mole. The very close virus-host associations apparent through phylogenetic analyses of ACDV and BRGV, as well as for many other hantaviruses, are suggestive of co-evolution. On the other hand, mole-borne hantaviruses have been found in each of the four hantavirus genera, with evidence of host switching $[9,19,20,22,33]$. In other words, mole-borne hantaviruses appear to be more catholic, or eclectic, in their host proclivity than rodent-borne hantaviruses, suggesting that ancestral moles may have served as the early hosts of primordial hantaviruses [1].

The high prevalence of ACDV infection detected in Siberian moles suggests efficient transmission between individuals. Most probably, moles have a high risk of virus exposure due to spending their entire life underground. Hantaviruses are known to survive for prolonged periods in external environments [34]. Conceivably, virus in excretions from infected moles is protected from ultraviolet sunlight inactivation and is efficiently transmitted. High prevalence of ACDV in Siberian moles is consistent with the similarly high positivity rate of NVAV in European moles [17,23].

The European mole is known to serve as the reservoir host of more than one hantavirus species, NVAV and BRGV [17]. By contrast to NVAV, only 4.6\% Talpa europaea were BRGV positive. We detected only ACDV among Siberian moles, possibly because only a limited number of specimens were tested. So, we are unable to conclude that NVAV or other NVAV-like hantaviruses are not hosted by Siberian moles.

The Siberian mole has a broad geographic range in the central part of Eurasia, spanning throughout the taiga zone of south-central Siberia in Russia, as far south as northern Mongolia and Kazakhstan. The high prevalence of ACDV in all three studied sites suggests that ACDV might be widespread throughout the distribution of Talpa altaica. Closely related virus and cyt B sequences of their hosts were detected in the site Academgorodok, located on the plains, while divergent virus strains and host mtDNA lineages were identified in the mountain site of Teletskoye. As previously shown, range expansions generally lead to a loss of genetic diversity along the expansion axis [35]. The low cyt B haplotype diversity, found in the northern plain territory (Academgorodok), might suggest rapid post glacial demographic expansion of Talpa altaica from the southern refugia in the Altai Mountains (Teletskoye) [36]. Site Azhendarovo is located close to the foothills of the Kuznetsk Alatau Mountains, in the contact zone of taiga and steppe with a fragmented landscape. Thus, two mtDNA lineages might originate from different local populations.

\section{Conclusions}

ACDV represents the seventh mole-borne hantavirus species, thus further expanding the host range diversity. Intensive studies are warranted to search for genetically distinct hantaviruses in other Talpa species, as well as in other New and Old World members of the Talpidae family.

Supplementary Materials: The following supporting information can be downloaded at: https:// www.mdpi.com/article/10.3390/v14020309/s1, Table S1: Oligonucleotide primers for amplification of the S- and M-segments of soricine mole-borne hantaviruses.

Author Contributions: Conceived and designed the experiments: L.N.Y.; collected the samples: V.V.P., S.A.A., E.M.L., T.A.D. and A.V.K.; performed the experiments: L.N.Y., N.A.S. and S.A.; analyzed the data: L.N.Y., S.A.A., S.A. and R.Y.; wrote and edited the paper: L.N.Y., S.A.A., S.A. and R.Y. All authors have read and agreed to the published version of the manuscript.

Funding: This research was funded by the state assignment of FBRI SRC VB VECTOR, Rospotrebnadzor, Russia; the Federal Fundamental Scientific Research Program for 2021-2025, Russia (Grant Number FWGS-2021-0002). 
Institutional Review Board Statement: The study was conducted in accordance with the Declaration of Helsinki and met the guideline requirements of the order of the Russian High and Middle Education Ministry (No. 742 issued on 13 November 1984) and by the Federal Law of the Russian Federation (No. 498-FZ issued on 19 December 2018). Field procedures and protocols were approved by the Institutional Animal Care and Use Committees of the Institute of Systematics and Ecology of Animals (Protocol 2020-02, 2021-01). The study did not involve endangered or protected species.

Informed Consent Statement: Not applicable.

Data Availability Statement: GenBank accession numbers for sequence data are available in Table 1 and in Figures 2 and 3. Other study data are available on request from the corresponding authors.

Acknowledgments: We thank Natalia Lopatina, from the Institute of Systematics and Ecology of Animals, for her valuable assistance in the field.

Conflicts of Interest: The authors declare no conflict of interest. The funding agencies had no role in study design, data collection and analysis, or preparation of the manuscript.

\section{References}

1. Yanagihara, R.; Gu, S.H.; Arai, S.; Kang, H.J.; Song, J.-W. Hantaviruses: Rediscovery and new beginnings. Virus Res. 2014, 187, 6-14. [CrossRef]

2. Arai, S.; Yanagihara, R. Genetic diversity and geographic distribution of bat-borne hantaviruses. Curr. Issues Mol. Biol. 2020, 39, 1-28. [CrossRef]

3. Jonsson, C.B.; Figueiredo, L.T.; Vapalahti, O. A global perspective on hantavirus ecology, epidemiology, and disease. Clin. Microbiol. Rev. 2010, 23, 412-444. [CrossRef]

4. $\quad$ Clement, J.; Maes, P.; Lagron, K.; Ranst, M.; Lameire, N. A unifying hypothesis and a single name for a complex globally emerging infection: Hantavirus disease. Eur. J. Clin. Microbiol. Infect. Dis. 2012, 31, 1-5. [CrossRef]

5. Heinemann, P.; Tia, M.; Alabi, A.; Anon, J.C.; Auste, B.; Essbauer, S.; Gnionsahe, A.; Kigninlman, H.; Klempa, B.; Kraef, C.; et al. Human infections by non-rodent-associated hantaviruses in Africa. J. Infect. Dis. 2016, 214, 1507-1511. [CrossRef]

6. Wei, Z.; Shimizu, K.; Nishigami, K.; Tsuda, Y.; Sarathukumara, Y.; Muthusinghe, D.S.; Gamage, C.D.; Granathne, L.; Lokupathirage, S.M.W.; Nanayakkara, N.; et al. Serological methods for detection of infection with shrew-borne hantaviruses: Thottapalayam, Seewis, Altai, and Asama viruses. Arch. Virol. 2021, 166, 275-280. [CrossRef] [PubMed]

7. Maes, P.; Adkins, S.; Alkhovsky, S.V.; Avšič-Županc, T.; Ballinger, M.J.; Bente, D.A.; Beer, M.; Bergeron, E.; Blair, C.D.; Briese, T.; et al. Taxonomy of the order Bunyavirales: Second update 2018. Arch. Virol. 2019, 164, 927-941. [CrossRef] [PubMed]

8. Vapalahti, O.; Lundkvist, A.; Fedorov, V.; Conroy, C.J.; Hirvonen, S.; Plyusnina, A.; Nemirov, K.; Fredga, K.; Cook, J.A.; Niemimaa, J.; et al. Isolation and characterization of a hantavirus from Lemmus sibiricus: Evidence for host switch during hantavirus evolution. J. Virol. 1999, 73, 5586-5592. [CrossRef]

9. Kang, H.J.; Bennett, S.N.; Dizney, L.; Sumibcay, L.; Arai, S.; Ruedas, L.A.; Song, J.W.; Yanagihara, R. Host switch during evolution of a genetically distinct hantavirus in the American shrew mole (Neurotrichus gibbsii). Virology 2009, 388, 8-14. [CrossRef] [PubMed]

10. Ling, J.; Sironen, T.; Voutilainen, L.; Hepojoki, S.; Niemimaa, J.; Isoviita, V.M.; Vaheri, A.; Henttonen, H.; Vapalahti, O. Hantaviruses in Finnish soricomorphs: Evidence for two distinct hantaviruses carried by Sorex araneus suggesting ancient host-switch. Infect. Genet. Evol. 2014, 27, 51-61. [CrossRef]

11. Kang, H.J.; Gu, S.H.; Yashina, L.N.; Cook, J.A.; Yanagihara, R. Highly divergent genetic variants of soricid-borne Altai virus (Hantaviridae) in Eurasia suggest ancient host-switching events. Viruses 2019, 11, 857. [CrossRef] [PubMed]

12. Liphardt, S.W.; Kang, H.J.; Dizney, L.J.; Ruedas, L.A.; Cook, J.A.; Yanagihara, R. Complex history of codiversification and host switching of a newfound soricid-borne orthohantavirus in North America. Viruses 2019, 11, 637. [CrossRef] [PubMed]

13. Guterres, A.; de Oliveira, R.C.; Fernandes, J.; de Lemos, E.R.S. The mystery of the phylogeographic structural pattern in rodent-borne hantaviruses. Mol. Phylogenet. Evol. 2019, 136, 35-43. [CrossRef] [PubMed]

14. Li, D.; Schmaljohn, A.L.; Anderson, K.; Schmaljohn, C.S. Complete nucleotide sequences of the M and S segments of two hantavirus isolates from California: Evidence for reassortment in nature among viruses related to hantavirus pulmonary syndrome. Virology 1995, 206, 973-983. [CrossRef] [PubMed]

15. Razzauti, M.; Plyusnina, A.; Sironen, T.; Henttonen, H.; Plyusnin, A. Analysis of Puumala hantavirus in a bank vole population in northern Finland: Evidence for co-circulation of two genetic lineages and frequent reassortment between strains. J. Gen. Virol. 2009, 90, 1923-1931. [CrossRef]

16. Klempa, B. Reassortment events in the evolution of hantaviruses. Virus Genes 2018, 54, 638-646. [CrossRef] [PubMed]

17. Laenen, L.; Vergote, V.; Kafetzopoulou, L.E.; Wawina, T.B.; Vassou, D.; Cook, J.A.; Hugot, J.P.; Deboutte, W.; Kang, H.J.; Witkowski, P.T.; et al. A novel hantavirus of the European mole, Bruges virus, is involved in frequent Nova virus coinfections. Genome Biol. Evol. 2018, 10, 45-55. [CrossRef]

18. Liphardt, S.W.; Kang, H.J.; Arai, S.; Gu, S.H.; Cook, J.A.; Yanagihara, R. Reassortment between divergent strains of Camp Ripley virus (Hantaviridae) in the northern short-tailed shrew (Blarina brevicauda). Front. Cell Infect. Microbiol. 2020, 10, 460. [CrossRef] 
19. Kang, H.J.; Gu, S.H.; Cook, J.A.; Yanagihara, R. Dahonggou Creek virus, a divergent lineage of hantavirus harbored by the long-tailed mole (Scaptonyx fusicaudus). Trop. Med. Health. 2016, 44, 16. [CrossRef]

20. Arai, S.; Ohdachi, S.D.; Asakawa, M.; Kang, H.J.; Mocz, G.; Arikawa, J.; Okabe, N.; Yanagihara, R. Molecular phylogeny of a newfound hantavirus in the Japanese shrew mole (Urotrichus talpoides). Proc. Natl. Acad. Sci. USA 2008, 105, 16296-16301. [CrossRef]

21. Kang, H.J.; Bennett, S.N.; Sumibcay, L.; Arai, S.; Hope, A.G.; Mocz, G.; Song, J.-W.; Cook, J.A.; Yanagihara, R. Evolutionary insights from a genetically divergent hantavirus harbored by the European common mole (Talpa europaea). PLoS ONE 2009, 4, e6149. [CrossRef] [PubMed]

22. Kang, H.J.; Bennett, S.N.; Hope, A.G.; Cook, J.A.; Yanagihara, R. Shared ancestry between a newfound mole-borne hantavirus and hantaviruses harbored by cricetid rodents. J. Virol. 2011, 85, 7496-7503. [CrossRef] [PubMed]

23. Gu, S.H.; Hejduk, J.; Markowski, J.; Kang, H.J.; Markowski, M.; Połatynska, M.; Sikorska, B.; Liberski, P.P.; Yanagihara, R. Co-circulation of genetically distinct soricid- and talpid-borne hantaviruses in Poland. Infect. Genet. Evol. 2014, $28,296-303$. [CrossRef] [PubMed]

24. Klempa, B.; Fichet-Calvet, E.; Lecompte, E.; Auste, B.; Aniskin, V.; Meisel, H.; Barrier, P.; Koivogue, L.; Meulen, J.; Krüger, D.H. Novel hantavirus sequences in shrew, Guinea. Emerg. Infect. Dis. 2007, 13, 520-522. [CrossRef] [PubMed]

25. Abascal, F.; Zardoya, R.; Telford, M.J. TranslatorX: Multiple alignment of nucleotide sequences guided by amino acid translations. Nucleic Acids Res. 2010, 38, W7-W13. [CrossRef]

26. Hall, T.A. BioEdit: A user-friendly biological sequence alignment editor and analysis program for Windows 95/98/NT. Nucleic Acids Symp. Ser. 1999, 41, 95-98.

27. Thompson, J.D.; Higgins, D.G.; Gibson, T.J. CLUSTAL W: Improving the sensitivity of progressive multiple sequence align-ment through sequence weighting, position-specific gap penalties and weight matrix choice. Nucleic Acids Res. 1994, 22, 4673-4680. [CrossRef]

28. Ronquist, F.; Huelsenbeck, J.P. MrBayes 3: Bayesian phylogenetic inference under mixed models. Bioinformatics 2003, 19, 1572-1574. [CrossRef]

29. Posada, D.; Crandall, K.A. MODELTEST: Testing the model of DNA substitution. Bioinformatics 1998, 14, 817-818. [CrossRef]

30. Posada, D. jModelTest: Phylogenetic model averaging. Mol. Biol. Evol. 2008, 25, 1253-1256. [CrossRef]

31. Yashina, L.N.; Kartashov, M.Y.; Wang, W.; Li, K.; Zdanovskaya, N.I.; Ivanov, L.I.; Zhang, Y.Z. Co-circulation of distinct shrew-borne hantaviruses in the far east of Russia. Virus Res. 2019, 272, 197717. [CrossRef] [PubMed]

32. Yashina, L.N.; Abramov, S.A.; Zhigalin, A.V.; Smetannikova, N.A.; Dupal, T.A.; Krivopalov, A.V.; Kikuchi, F.; Senoo, K.; Arai, S.; Mizutani, T.; et al. Geographic distribution and phylogeny of soricine shrew-borne Seewis virus and Altai virus in Russia. Viruses 2021, 13, 1286. [CrossRef] [PubMed]

33. Zhang, Y.Z. Discovery of hantaviruses in bats and insectivores and the evolution of the genus Hantavirus. Virus Res. 2014, 187, 15-21. [CrossRef] [PubMed]

34. Kallio, E.R.; Klingström, J.; Gustafsson, E.; Manni, T.; Vaheri, A.; Henttonen, H.; Vapalahti, O.; Lundkvist, Å. Prolonged survival of Puumala hantavirus outside the host: Evidence for indirect transmission via the environment. J. Gen. Virol. 2006, 87, 2127-2134. [CrossRef]

35. Hewitt, G.M. Some genetic consequences of ice ages, and their role in divergence and speciation. Biol. J. Lin. Soc. 1996, 58, 247-276. [CrossRef]

36. ̌ičánková, V.P.; Robovský, J.; Riegert, J. Ecological structure of Recent and Last Glacial mammalian faunas in northern Eurasia: The case of Altai-Sayan refugium. PLoS ONE 2014, 9, e85056. [CrossRef] 